\title{
Techniques in Coloproctology 2012-2013: message from the editors
}

\author{
M. Pescatori · G. Gagliardi
}

Received: 4 January 2013/Accepted: 11 January 2013/Published online: 1 February 2013

(C) Springer-Verlag Italia 2013

In 2012, submissions to Techniques in Coloproctology increased to 420 from 261 in 2011 and the journal became bimonthly. However, the rejection rate has not substantially changed: $60 \%$ in 2012 versus $64 \%$ in 2011. The time to first decision has actually decreased, from 40 days in 2011 to 34 days in 2012. This is in great part thanks to the hard work and expertise of our new editors Drs. Roberto Bergamaschi for laparoscopic surgery, Salvatore Pucciarelli for colorectal cancer and Steven D. Wexner for reviews and meta-analyses. The plan to create multi-disciplinary areas of interest and expertise will be extended in 2013 to the area of colorectal motility disorders that will be edited by Prof. Gabrio Bassotti. Dr. Ezio Falletto, who was Assistant Editor in 2012, will now become a member of the editorial board and oversee the submissions on sacral nerve stimulation. In 2013, Drs. Oded Zmora, current president of the ISCRS and Aldo Infantino, past president of the SICCR, will succeed to Drs. Yehiel Ziv and Carlo Ratto as co-editors. Our editorial board, representing 22 countries worldwide, has been updated. We thank the past members for their contribution and extend a warm welcome to the new members.
In 2010, the journal received its first IF of 1.533. In 2011, the IF was 1.288. The drop is due to the publication in 2010 of a congress supplement comprising 30 citable articles (more than a third of the citable articles published in that year), which gathered only 8 citations, most of them self-citations. Without these 30 articles and relative citations, the IF would have increased to 1.57 (or more if adjusting for self-citations), 0.04 higher than in 2010 . Unfortunately, by the time we realized this, another congress supplement with citable articles had been published in 2011. Increasing the quality and number of articles will likely compensate for these past mistakes.

Beginning in 2013, Dr. Gagliardi, who has been committed to this journal since 2006 and has been instrumental in furthering its growth, will work alongside Prof. Pescatori as Editor-in-Chief. We are confident that the journal, with its unique blend of international and interdisciplinary expertise, will increasingly become an essential point of reference for surgeons, gastroenterologists, urogynecologists and any other health professional caring for patients with colorectal and pelvic floor disease.

Conflict of interest None.

M. Pescatori $(\bowtie) \cdot$ G. Gagliardi

Parioli Clinic Coloproctology Unit,

Via F. Giordano 8, 00197 Rome, Italy

e-mail: ucpclub@virgilio.it 